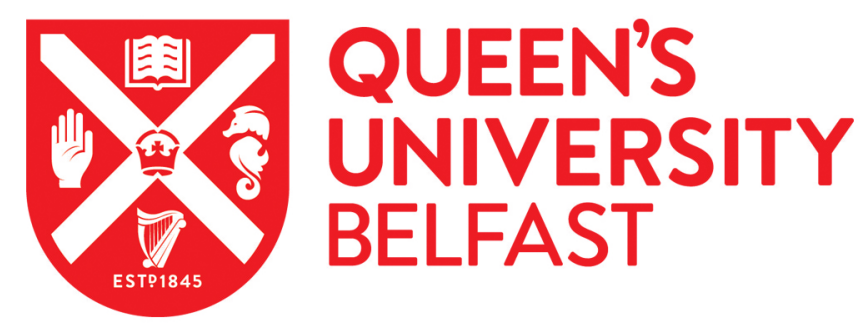

\title{
Effect of high pressure processing in combination with Weissella viridescens as a protective culture against Listeria monocytogenes in ready-to-eat salads of different $\mathrm{pH}$
}

Stratakos, A. C., Linton, M., Tessema, G. T., Skjerdal, T., Patterson, M. F., \& Koidis, A. (2016). Effect of high pressure processing in combination with Weissella viridescens as a protective culture against Listeria monocytogenes in ready-to-eat salads of different pH. Food Control, 61, 6-12.

https://doi.org/10.1016/j.foodcont.2015.09.020

\section{Published in:}

Food Control

Document Version:

Peer reviewed version

Queen's University Belfast - Research Portal:

Link to publication record in Queen's University Belfast Research Portal

\section{Publisher rights}

( 2015. This manuscript version is made available under the CC-BY-NC-ND 4.0 license http://creativecommons.org/licenses/by-nc-nd/4.0/ which permits distribution and reproduction for non-commercial purposes, provided the author and source are cited.

\section{General rights}

Copyright for the publications made accessible via the Queen's University Belfast Research Portal is retained by the author(s) and / or other copyright owners and it is a condition of accessing these publications that users recognise and abide by the legal requirements associated with these rights.

Take down policy

The Research Portal is Queen's institutional repository that provides access to Queen's research output. Every effort has been made to ensure that content in the Research Portal does not infringe any person's rights, or applicable UK laws. If you discover content in the

Research Portal that you believe breaches copyright or violates any law, please contact openaccess@qub.ac.uk. 
1 Effect of high pressure processing in combination with Weissella viridescens as a 2 protective culture against Listeria monocytogenes in ready-to-eat salads of different $\mathrm{pH}$

4 Alexandros Ch. Stratakos a , Mark Linton b, Girum Tadesse Tessema c, Taran Skjerdal c, 5 Margaret F. Patterson ${ }^{\mathrm{b}}$, Anastasios Koidis ${ }^{\mathrm{a}^{*}}$

6 a Queen’s University Belfast, Institute for Global Food Security, Belfast, Northern Ireland, UK.

$7 \quad$ b Agri-Food \& Biosciences Institute, Belfast, Northern Ireland, UK.

$8 \quad{ }^{\mathrm{c}}$ National Veterinary Institute, Oslo, Norway

9

10

$11 *$ Corresponding author

12 Dr Anastasios (Tassos) Koidis

13 Institute for Global Food Security

14 Queen's University Belfast

$15 \quad$ 18-30 Malone Road

16 Belfast, BT9 5BN

17 Northern Ireland, UK

18 Tel: +44 2890975569

19 email: t.koidis@qub.ac.uk 


\section{Abstract}

This study explored the effect of HPP (400 MPa/1 min) and a Weissella viridescens protective culture, alone or in conjunction, against L. monocytogenes in ready-to-eat (RTE) salads with different $\mathrm{pH}$ values (4.32 and 5.59) during storage at 4 and $12^{\circ} \mathrm{C}$. HPP was able to reduce the counts of the pathogen after treatment achieving approximately a 4.0 and $1.5 \log \mathrm{CFU} / \mathrm{g}$ reduction in the low and higher $\mathrm{pH}$ RTE salad, respectively. However, L. monocytogenes was able to recover and grow during subsequent storage. $W$. viridescens grew in both RTE salads at both storage temperatures, with HPP resulting in only a small immediate reduction of $W$. viridescens ranging from 0.50 to $1.2 \mathrm{log} \mathrm{CFU} / \mathrm{g}$ depending on the $\mathrm{pH}$ of the RTE salad. For the lower pH RTE salad, the protective culture was able to gradually reduce the $L$. monocytogenes counts during storage whereas for the higher pH RTE salad in some cases it delayed growth significantly or exerted a bacteriostatic effect. exerted a bacteriostatic effect. The results revealed that the increased storage temperature led to an increase in the inactivation/inhibition of $L$. monocytogenes in the presence of $W$. viridescens. The combination of HPP and $W$. viridescens is a promising strategy to control L. monocytogenes and can increase safety even when a break in the chill chain occurs.

Keywords: protective culture, Weissella viridescens, Listeria monocytogenes, high pressure, temperature, $\mathrm{pH}$ 


\section{INTRODUCTION}

Listeria monocytogenes is an important foodborne pathogenic microorganism and the causative agent of listeriosis, which has a significant impact on public health and economy (Scallan et al., 2011; Stephan et al., 2015; EFSA 2015). Due to the high mortality rate associated with listeriosis, it ranks in a global scale amongst the most frequent causes of death due to foodborne illnesses (Behravesh et al., 2011; Werber et al., 2013; EFSA, 2014). L. monocytogenes can survive and grow in a variety of foods, surfaces and equipment under adverse environmental conditions such as low $\mathrm{pH}$, low water activity $\left(\mathrm{a}_{\mathrm{w}}\right)$ and low temperature (Angelidis, Smith, \& Smith, 1999; Hado \& Yousef, 2007). Ready-to-eat (RTE) products have been implicated in several listeriosis outbreaks worldwide (Swaminathan \& Gerner-Smidt 2007; Johnsen, Lingaas, Dag Torfoss, Strøm, \& Nordøy, 2010; Shi, Qingping, Jumei, Moutong, Zean, 2015). Therefore, reducing the occurrence of L. monocytogenes in RTE foods is an important food safety goal for the food industry. High pressure processing (HPP) has been gaining increasing importance as a potential non-thermal preservation technology for different types of products including RTE foods. In contrast to thermal treatments, HPP results in minimal or no effects on nutritional or quality characteristics and at the same time can lead to microorganism inactivation (Cheftel, 1995). HPP inactivates microbial cells by inducing physical damage and altering the functionality of the cytoplasmic membrane, causing protein denaturation and interfering with genetic mechanisms (Patterson, 2005). In general, studies have shown that vegetative microorganisms present in food are inactivated at pressure levels between 400 and 600 MPa for several minutes (Smith, Mendonca, \& Jung, 2009; Patterson, McKay, Connolly, \& Linton, 2010; Stratakos \& Koidis, 2015). However, as HPP is a batch process and due to the fact that in some cases (i.e. application of high pressure levels) it can result in negative effects on quality (e.g. increased lipid oxidation, texture changes) (Stratakos \& Koidis, 2015), from a commercial perspective it is more desirable to use as short 
a treatment time as possible and as low a pressure as possible in order to achieve a high throughput and minimise any potential effects on quality as well as reduce equipment/metal fatigue due to repeated usage (Mertens \& Deplace 1993).

Therefore, combining HPP with other preservation methods could allow the use of milder pressure treatments to achieve additive or synergistic effects against pathogenic microorganisms. Biopreservation has also been used in recent years as a way of prolonging shelf life and increasing safety of RTE products (Pilet \& Leroi 2011; Liu et al. 2012), with various studies showing the synergistic effect between HHP and bacteriocins on inactivation of foodborne pathogenic microorganisms and prevention of microbial spoilage (Jofré, Garriga, \& Aymerich, 2008; Chung, Vurma, Turek, Chrism, \& Tousef, 2005; Chung \& Yousef, 2010). In these studies, the bacteriocin was added or sprayed directly on the food. Direct addition of bacteriocin implies that it has been produced ex-situ by a producer strain with subsequent concentration and purification steps which can be expensive and time consuming (Gálvez, Abriouel, López, \& Omar 2007). Moreover, loss of bacteriocin activity might occur due to enzymatic degradation and interaction with food proteins and lipids (Holzapfel, Geisen, \& Schillinger, 1995). To circumvent the above problems in-situ bacteriocin production by lactic acid bacteria (LAB) has been also investigated against pathogenic microorgansims (Mataragas, Drosinos, \& Metaxopoulos, 2003; Brillet, Pilet, Prévost, Cardinal \& Leroi, 2005). The effect of these LAB protective cultures against other microorganisms has been attributed to the competition for nutrients and/or production of antimicrobial compounds such as organic acids, enzymes, bacteriocins and reuterin (Holzapfel et al., 1995).

The aim of the study was to explore the possibility of using a $W$. viridescens protective culture and HPP, either alone or in conjunction, to help control the growth of L. monocytogenes. This W. viridescens strain has been shown to have antimicrobial properties and does not cause 
antimicrobial activity has not been identified yet. The efficiency of the above approach was tested on RTE salads with different $\mathrm{pH}$ values and during refrigeration and abuse storage temperatures.

\section{MATERIAL AND METHODS}

\subsection{Preparation of Listeria monocytogenes inoculum}

For each L. monocytogenes strain used i) LR102 (Camembert, outbreak isolate; serotype 1/2a, ii) VI 51028 (fish slaughter house; serotype 4), iii) 0227-359 (meatballs; serotype 1), iv) 0113131 (RTE chicken; serotype 1) and v) VI 51010 (L. monocytogenes Scott A; serotype 4b), a loopful of a fresh tryptone soya agar (Oxoid code CM0131, Oxoid, Basingstoke, UK) plus 0.6 \% yeast extract (Oxoid code LP0021) (TSAYE) slope culture was transferred into $10 \mathrm{ml}$ of brain heart infusion broth (BHI) (Oxoid code CM1135) and incubated at $37^{\circ} \mathrm{C}$ for $24 \mathrm{~h}$. Subsequently $100 \mu \mathrm{l}$ of a $10^{-4}$ dilution of this broth was transferred into another $10 \mathrm{ml} \mathrm{BHI}$ broth and incubated at $37^{\circ} \mathrm{C}$ for $48 \mathrm{~h}$, in order to reach the stationary phase of growth. The final $10 \mathrm{ml}$ cultures were centrifuged at $3600 \times \mathrm{g}$, for $30 \mathrm{~min}$, washed twice in phosphate buffered saline (PBS) and the pellet re-suspended in a final volume of $10 \mathrm{ml}$ PBS to give approximately $10^{9} \mathrm{CFU} / \mathrm{ml}$. Subsequently, equal quantities of the 5-strain cell suspensions were mixed well in a plastic $50 \mathrm{ml}$ centrifuge tube to produce the 5 -strain cocktail. $100 \mu$ of this suspension were inoculated into the RTE salad samples (10 $\pm 0.2 \mathrm{~g})$, to give an initial inoculum level of approximately 7 log CFU/g. Samples were massaged for approx. 30 sec to ensure uniform distribution of the inoculum.

\subsection{Preparation of Weissella viridescens inoculum}


115 A W. viridescens strain that was previously isolated from cooked chicken in the Agri-Food and

116 Biosciences Institute was used because it is quite salt and $\mathrm{pH}$ tolerant (Mol, Hietbrink, Mollen,

117 \& van Tinteren, 1971) and was found to have antimicrobial activity and relatively resistant to

118 pressure (Patterson, Mackle, \& Linton, 2011). A loopful from a MRS agar (Oxoid code 119 CM1153B) slope culture was transferred into a $10 \mathrm{ml}$ MRS broth (Oxoid code CM0359B) and 120 incubated for $24 \mathrm{~h}$ at $30^{\circ} \mathrm{C}$ under anaerobic conditions. Afterwards, $100 \mu \mathrm{l}$ of this broth was transferred into another $10 \mathrm{ml}$ MRS broth and incubated at $30^{\circ} \mathrm{C}$ for $72 \mathrm{~h}$, in order to allow for the microorganism to reach the stationary phase of growth. After the completion of the incubation, $100 \mu \mathrm{l}$ of this suspension was inoculated into the RTE salad samples (10 $\pm 0.2 \mathrm{~g})$, at a level of approximately $5 \log$ CFU/g. The inoculation of $W$. viridescens into the RTE salad samples was performed approximately 30 min after the L. monocytogenes inoculation.

\subsection{Preparation of RTE salads}

The RTE salads were prepared in-house using a commercial recipe. Two different salads were prepared with two different final $\mathrm{pH}$ values (low and higher). The higher $\mathrm{pH} \mathrm{RTE}$ salad was prepared by slightly altering the initial formulation to achieve the increase in $\mathrm{pH}$ (Table 1). All samples were packaged using polyethylene/polyamide vacuum pouches (Scobie and Junor, Mallusk, Northern Ireland). The following four treatments, all inoculated with a 5-strain cocktail of L. monocytogenes, were employed in this study:

- Control (C): vacuum-packed RTE salad.

- $\quad$ Pressure treatment (HPP): vacuum-packed RTE salad samples pressure treated at 400 MPa for 1 min.

- W. viridescens protective culture (PC): inoculated with W. viridescens and vacuumpacked. 
- HPP/PC: inoculated with W. viridescens, vacuum-packed, and pressure treated at 400 MPa for 1 min.

All samples were stored for a period of 21 days at 4 and $12^{\circ} \mathrm{C}$.

\subsection{Characterisation of RTE salads}

144 The $\mathrm{pH}$ of the salads was determined with the use of a Jenway pH Meter Model 3505, after mixing with deionised water at a ratio of $1: 1$. Water activity $\left(a_{w}\right)$ was measured by means of a Hygrolab $3 \mathrm{a}_{\mathrm{w}}$ meter (Rotronic instruments, UK). Three replicate samples from different production runs were used for the measurements.

\section{$2.5 \quad$ Irradiation treatment}

Packaged samples were sterilised by gamma irradiation after delivering a dose of $25 \mathrm{kGy}$, using $a^{60}$ Co Gamma-beam 650 facility (Nordion, Canada). The samples underwent cold sterilisation in order to be able to get a clear picture of the interaction between $L$. monocytogenes, $W$. viridescens and high pressure processing. After irradiation, random samples from all batches were tested to confirm sterility.

\subsection{High pressure processing}

Pressure treatment of packaged RTE salad samples was performed in a commercial scale high pressure press (Quintus 35L, Avure Technologies, U.S.A.), with a pressure vessel of $35 \mathrm{~L}$ volume. The pressure transmission fluid used was potable water. The pressure come-up time was approximately 25 sec per $100 \mathrm{MPa}$ and the pressure release time was approximately $10 \mathrm{~s}$.

The initial temperature of the water was approximately $18^{\circ} \mathrm{C}$ and the temperature increase due to adiabatic heating was approximately $2-3^{\circ} \mathrm{C}$ per $100 \mathrm{MPa}$. The processing conditions were $400 \mathrm{MPa}$ with a hold time at that pressure level of $1 \mathrm{~min}$. 


\subsection{Listeria monocytogenes enumeration}

166 Samples were opened aseptically and the contents were transferred to a sterile stomacher bag

167 with a filter insert (Interscience, St. Nom La Breteche, France). A $10^{-1}$ dilution of the sample 168 was prepared by adding $90 \mathrm{ml}$ of maximum recovery diluent (MRD) (Oxoid code CM733). 169 The dilution was homogenised for $1 \mathrm{~min}$ in a Seward stomacher. If necessary, further 10-fold 170 dilutions were prepared in $9 \mathrm{ml}$ MRD. For enumeration of $L$. monocytogenes, $100 \mu 1$ of each 171 of the 10-fold dilutions were spread plated onto Oxoid chromogenic Listeria agar (OCLA) 172 (Oxoid, code CM1084B) supplemented with OCLA selective supplement (Oxoid code 173 SR0226E) and Brilliance Listeria differential supplement (Oxoid code SR0228E) and 174 incubated at $37^{\circ} \mathrm{C}$ for $48 \mathrm{~h}$. Each sample was plated in duplicate.

\subsection{Weissella viridescens enumeration}

177 The enumeration of $W$. viridescens was performed as for L. monocytogenes. $100 \mu l$ of the appropriate dilutions were spread plated onto MRS agar plates and incubated at $30^{\circ} \mathrm{C}$ for $48 \mathrm{~h}$ under anaerobic conditions. The five strains of $L$. monocytogenes used in this study were not found to grow on MRS agar (Patterson et al., 2011).

\subsection{Statistical analysis}

The experiment was performed three times on different occasions in order to obtain three independent replicates. Factorial analysis of variance was used to determine the interactions between treatment, storage, storage temperature and $\mathrm{pH}$ on the microbial counts obtained. A significance level of 0.05 was used. When microbial counts were below the detection limit (50 CFU/g) this was taken as the value for the statistical tests. 


\section{RESULTS AND DISCUSSION}

\subsection{Fate of $L$. monocytogenes in low-pH RTE salad at 4 and $12^{\circ} \mathrm{C}$}

191

192

The formulation, $\mathrm{pH}$ and $\mathrm{a}_{\mathrm{w}}$ values of the RTE salads are shown in Table 1. Statistical analysis showed that the different formulation of the salads led to significantly different $\mathrm{pH}$ values. Figure 1 presents the behaviour of L. monocytogenes (A and C) and W. viridescens (B and D) during storage at refrigeration and abuse temperature. Although, the initial level of the pathogen (approx. 7 log CFU/g.) chosen to be used is unlikely to occur in real-life scenarios and it might affect the subsequent behaviour of $L$. monocytogenes (Tyrovouzis et al., 2014), its use was deemed necessary to clearly elucidate the potential growth or inactivation of the pathogen during storage. Furthermore, in order to selectively enumerate the target microorganisms and clearly demonstrate the effect of $W$. viridescens against $L$. monocytogenes in a food matrix the samples were cold sterilised.

It has been hypothesised that $W$. viridescens produces a small, diffusible compound which is able to inhibit the growth of both Gram-negative and Gram-positive microorganisms (Patterson et al., 2010). Weissella paramesenteroides has been found to produce a small ( $\sim 2.5 \mathrm{kDa})$ nonproteinaceous compound that shows an antimicrobial effect (Pal \& Ramana, 2009). Moreover, a bacteriocin called Weissellicin 110 has been recently identified which is produced by a strain of Weissella cibaria (Srionnual, Yanagida, Lin, Hsiao, \& Chen, 2007).

Statistical analysis for $L$. monocytogenes counts revealed that there was a significant interaction between treatment, $\mathrm{pH}$, storage and temperature $(\mathrm{P}=0.009)$. For the lower-pH salad, $L$. monocytogenes inoculated in control samples remained at the same level during storage at $4^{\circ} \mathrm{C}$ (Fig. 1A) showing that the $\mathrm{pH}$ value of the RTE salad, although it did not result in the inactivation of the pathogen, was able to inhibit its growth. 
HPP treatment resulted in a significant reduction of $L$. monocytogenes counts. Subsequently the counts remained relatively stable showing the same trend as the control samples. On the other hand, counts of L. monocytogenes in the presence of the PC showed a gradual decrease during storage. This decrease became significant $(\mathrm{P}<0.001)$ after six days of storage and at day 21 the pathogen counts were approximately $4 \log$ CFU/g, achieving an approximately $3.37 \log$ average count reduction compared to the controls. Vermeiren, Devlieghere, De Graef, \& Debevere (2004) have also found that Lactobacillus sakei had antimicrobial activity against $L$. monocytogenes inoculated on cooked ham. In an another study, the application of Carnobacterium divergens M35 was able to reduce the L. monocytogenes counts in cold smoked salmon by $3.1 \log \mathrm{CFU} / g$ after 21 days of storage at $4^{\circ} \mathrm{C}$ (Tahiri, Desbiens, Kheadr, Lacroix, \& Fliss, 2009).

When the two methods were used in conjunction (HPP/PC) a decrease in the counts of the pathogen were also observed. However in this case L. monocytogenes could not be enumerated from the third sampling point (6 days storage) onward and until the end of storage. One of the main sites of damage induced by pressure is the cell membrane (Patterson, 2005). The use of high pressure in conjunction with bacteriocins has been shown to lead to increased antimicrobial activity (Kalchayanand, Sikes, Dunne, \& Ray 1998; Chung \& Yousef, 2010). The physical damage and/or permeabilisation of the membrane due to HPP could lead to increased entry of the antimicrobial compound(s) produced by $W$. viridescens during its growth. The presence of this antimicrobial(s) could possibly inhibit recovery of sub-lethally pressure-injured cells by interfering with several biological mechanisms (e.g. production of required biological materials). The use of non-selective medium overlaid with selective medium (Lorentzen et al., 2010) or the ISO 11290-2 assay in addition to the selective media used here would have given even more information on the extent of pressure-damaged cells as it would permit their enumeration in damaged cells in contrast to selective media. 
236 For lower-pH samples stored at $12^{\circ} \mathrm{C}$ (Fig 1C) a similar trend was observed for the control

237 samples in which the populations of $L$. monocytogenes remained relatively stable during

238

239 storage. For HPP samples, L. monocytogenes counts remained at the same levels after the initial reduction despite of the elevated temperature showing again the inhibitory effect of the low $\mathrm{pH}$. PC treatment at $12^{\circ} \mathrm{C}$ also led to a significant gradual reduction of the pathogen counts. However at this temperature at the end of the storage the average pathogen counts were $2 \log$ CFU/g indicating that the protective culture had an increased bactericidal effect at the abuse temperature. Statistical analysis showed that after day 3 for the PC treatment the $L$. monocytogenes counts at $12^{\circ} \mathrm{C}$ were always statistically significantly lower compared to the counts for the PC treatment during storage at $4^{\circ} \mathrm{C}$. The combination of HPP and PC resulted in a reduction below the enumeration limit throughout storage in the abuse temperature too. However, it should be noted that L. monocytogenes decreased below the enumeration limitfrom the second sampling point (3 days storage) forward, three days sooner compared to the refrigeration temperature, again revealing a more pronounced antimicrobial effect. From these results it is obvious that the storage at the abuse temperature was more detrimental to the survival of $L$. monocytogenes when $W$. viridescens was present. The results of this experiment are consistent with the study of Angelidis, Boutsiouki, \& Papageorgiou, (2010) that showed that increased inactivation rates were observed for $L$. monocytogenes counts inoculated in cheese, during storage at $22^{\circ} \mathrm{C}$ compared to storage at 12 and $4^{\circ} \mathrm{C}$. Fig. $1 \mathrm{~B}$ and Fig. $1 \mathrm{D}$ present the behaviour of $W$. viridescens in RTE salad (PC and HPP/PC treatments). $W$. viridescens grew rapidly in the low-pH RTE salad with the counts reaching approximately 7 log CFU/g after 6 days during of storage at $4^{\circ} \mathrm{C}$. However, when samples were pressure treated (HPP/PC) a prolongation of the lag phase was evident. Following the end of the lag phase average counts increased rapidly reaching $6.43 \mathrm{log}$ CFU/g at day 9. The observed extension of the lag phase can be attributed to the sub-lethal injuries induced to the microbial cells due to pressure 
261 (Tholozan, Ritz, Jugiau, Federighi, \& Tissier, 2000). On the other hand, W. viridescens grew faster in the abuse temperature $(\mathrm{P}<0.001)$ and reached $8.13 \log \mathrm{CFU} / \mathrm{g}$ at day 6 . It is noteworthy that a shorter or no lag phase was observed for pressure-treated samples (HPP/PC) at the abuse temperature which allowed average counts to reach $8.06 \log$ CFU/g at day 6. Due to the limited initial sampling we could not determine precisely the absence or length of the lag phase. The increased storage temperature enabled the cells to recover fast from the sub-lethal injuries and commence growth (Bull, Hayman, Stewart, Szabo, \& Knabel, 2005; Stratakos, DelgadoPando, Linton, Patterson, \& Koidis, 2015a; Stratakos, Linton, Patterson, \& Koidis, 2015b).

\subsection{Fate of L. monocytogenes and $W$. viridescens in higher pH RTE salad at 4 and} $12^{\circ} \mathrm{C}$

The results on the behaviour of $L$. monocytogenes and $W$. viridescens in RTE salads with a higher initial $\mathrm{pH}$ are illustrated in Figures 2 (A-D). The higher $\mathrm{pH}$ of this version of the RTE salad permitted the growth of $L$. monocytogenes. For the control samples stored at $4^{0} \mathrm{C}$ the counts of $L$. monocytogenes increased rapidly during storage reaching $>8$ log CFU/g after 6 days. With regards to the PC treatment at day 3 a reduction was observed in the counts of the pathogen compared to the control. However, after this initial reduction, growth commenced again and after day 9 of storage there were no statistically significant differences in $L$. monocytogenes average counts between the control and PC treatments. For the HPP trials a lower immediate reduction was observed after treatment (see 3.3) and the exponential stage of growth started after the end of a 6-day lag phase. L. monocytogenes counts for the HPP and HPP/PC trials showed no statistical significant differences $(\mathrm{P}>0.05)$ until day 6 of storage. Beyond this point significant differences were found between the two treatments. The presence of $W$. viridescens (HPP/PC) was able to delay the growth of pathogen which reached 6.95 log 

3 days storage. In this case the PC treatment did not result in reduction but exerted a bacteriostatic effect until day 9 after which growth of the pathogen commenced again. The HPP treatment was not sufficient to control the growth of the pathogen with the exponential stage of growth starting only after 3 days storage. When the two methods were combined (HPP/PC) a clear bacteriostatic effect was observed until the end of storage (5.39 log CFU/g at end of storage). In this case as well, the elevated storage temperature allowed for a better control of the growth of L. monocytogenes even in the RTE salad with a more favourable $\mathrm{pH}$ for its growth. Carnobacterium divergens V41 inoculated on cold smoked salmon has also been found to be able to inhibit the growth of L. monocytogenes during storage for 28 days at 4 and $8^{\circ} \mathrm{C}$ with minimal effects on the quality of the product (Brillet et al. 2005).

W. viridescens counts showed a similar trend to the low-pH RTE salad stored both at 4 and $12^{0} \mathrm{C}$ (Fig 2B and 2d). W. viridescens grew well in this product too and reached at day 6 of storage 7.34 and $6.56 \log \mathrm{CFU} / \mathrm{g}$ for PC and HPP/PC, respectively for samples stored at $4^{0} \mathrm{C}$ and 8.15 and $8.06 \log \mathrm{CFU} / \mathrm{g}$, respectively for samples stored at $12^{\circ} \mathrm{C}$. A shorter or no lag phase was also evident for the HPP/PC treatment at $12^{\circ} \mathrm{C}$.

In general, the increased antimicrobial effect observed at the abuse temperature for the PC and HPP/PC treatments can be attributed to the higher counts of the $W$. viridescens due to the absence of the lag phase and possibly to the increased metabolic activity of the $L$. monocytogenes due to higher temperature which led to an enhanced lethal effect of the antimicrobial compound(s) produced by $W$. viridescens. An increased death rate at abuse temperatures compared to refrigeration temperatures has also been observed for $E$. coli O157:H7 and Salmonella Typhimurium DT104 inoculated on pepperoni (Faith, Parniere, 


\subsection{Effect of $\mathrm{pH}$ on $L$. monocytogenes and $W$. viridescens}

312

313

314

315

\subsubsection{Effect of pH on HPP inactivation of L. monocytogenes and W. viridescens}

The level of pressure induced inactivation was found to be significantly different $(\mathrm{P}<0.05)$ depending on the $\mathrm{pH}$ of the RTE salad, for both microorganisms. The low-pH resulted in a much higher average reduction $(\mathrm{P}=0.01$ ) in the L. monocytogenes counts (approx. 4 log CFU/g) compared to the salad with the higher $\mathrm{pH}$, which showed a 1.51 log CFU/g average reduction. Jung et al., (2013) found that pressure treatment at $300 \mathrm{MPa}$ for 5 min resulted in $>6$ log reduction in L. monocytogenes counts in PBS adjusted to $\mathrm{pH} 4$ compared to $<1$ log reduction at $\mathrm{pH}$ 7.2. Pressurization (345 MPa) at $\mathrm{pH} 4.5$ increased inactivation of L. monocytogenes in PBS by an additional 1.2 - 3.9 log cycles at pH 4.5 compared to a pH 6.5 (Alpas, Kalchayanand, Bozoglu, \& Ray, 2000). This increase in pressure induced inactivation as the $\mathrm{pH}$ decreases has also been confirmed in studies with real food. Specifically, the survival of Escherichia coli O157:H7 in orange juice was increasingly reduced as $\mathrm{pH}$ values of the juice decreased (Linton, McClements, \& Patterson, 1999). With regards to W. viridescens, HPP treatment (HPP/PC) resulted in statistically significant reductions in counts for both RTE salads $(<0.5$ and $1.12 \log \mathrm{CFU} / \mathrm{g}$ for the higher and lower $\mathrm{pH}$ salads, respectively). However, these relatively low reductions did not prevent it from exerting its protective effect against $L$. monocytogenes during storage. Park, Sohn, Shin, \& Lee, (2001) found that HPP treatment of 600 MPa for 5 min resulted in approximately 4 log CFU/g reduction of $W$. viridescens counts in ham. In general, lactic acid bacteria are tolerant to low $\mathrm{pH}$, so it is not surprising that $W$. viridescens was able to tolerate low $\mathrm{pH}$ values and therefore a relatively small reduction was observed in the low pH product.

\subsubsection{Effect of pH on L. monocytogenes and W. viridescens during storage}


335 The $\mathrm{pH}$ played an important role in the fate of L. monocytogenes during storage. According to 336 European Regulation (EC) No. 2073/2005, the lower-pH RTE salad falls under the category of 337 products $(\mathrm{pH} \geq 4.4)$ that do not support the growth of $L$. monocytogenes. Therefore, a very 338 different trend in the behaviour of L. monocytogenes was observed during storage between the 339 two types of salad stored at the same temperature both at $4^{\circ} \mathrm{C}$ (Fig. $1 \mathrm{~A}$ and Fig. $2 \mathrm{~A}$ ) and $12^{\circ} \mathrm{C}$ 340 (Fig. 1B and 2B) since the low $\mathrm{pH}$ was able to inhibit the growth but not lead to the inactivation 341 of the pathogen. For the low-pH RTE salad the pathogen counts of the PC and HPP/PC treatments dropped during storage (Fig. 1A and 1B) whereas for the higher pH salad (Fig. 2A and 2B) the counts remained in the same levels or increased.

344 The $W$. viridescens counts (PC treatments) did not show any significant differences during storage between low (Fig. 2B) and higher $\mathrm{pH}$ samples (Fig. 2D) ( $\mathrm{P}>0.05)$. On the other hand, HPP/PC treatments did show significant differences in the counts of $W$. viridescens during storage between the two different types of RTE salad. These significant differences observed in the latter case, were attributed to the different initial HPP-induced inactivation levels (see 3.3.1.). Overall, these results reveal that the $W$. viridescens protective culture showed similar growth potential in the two different $\mathrm{pH}$ values tested.

In this study, the low $\mathrm{pH}$ acted as an extra hurdle which in combination with the potential production of antimicrobial compound(s) probably contributed towards the metabolic exhaustion of the L. monocytogenes cells. When the low $\mathrm{pH}$ hurdle was removed (in the RTE salad with the higher $\mathrm{pH}$ ) the bactericidal effect was substituted with substituted in most cases with a significant delay in growth or exerted a bacteriostatic effect. The results showed that $W$. viridescens alone or in combination with HPP, is able to be used as a protective culture in RTE salads with different $\mathrm{pH}$ values, as it can grow well and exhibit antilisterial activity and thus offer an increased safety margin. 


\section{CONCLUSIONS}

361 The application of this strain of $W$. viridescens has significant potential as a protective 362 culture/biopreservation method because it can successfully be used to help control the growth of L. monocytogenes in low and higher pH RTE salads due to the possible antimicrobial(s) produced during its growth. The specificity of bacteriocins is not linked to LAB origin but is more likely linked to the bacterial species that produces them (Pilet \& Leroi, 2011) which means that $W$. viridescens could probably be used as a preservation method in other food products of plant and animal origin. HPP was able to significantly reduce the counts of $L$. monocytogenes in both types of RTE salads but the pathogen was able to recover during storage at abusive temperature. A relatively mild HPP treatment in conjunction with the $W$. viridescens protective culture exhibited a synergistic effect against $L$. monocytogenes which was even more pronounced during storage at abusive temperature. The combination of HPP and $W$. viridescens is a promising strategy to control L. monocytogenes is RTE salads of different $\mathrm{pH}$ and can increase safety even in a cold chain break scenario.

\section{Acknowledgements}

The research leading to these results has received funding from the European Union's Seventh Framework Programme for research, technological development and demonstration under grant agreement No. 289262. Theme KBBE.2011.2.1-01, research project STARTEC: "Decision Support Tools to ensure safe, tasty and nutritious Advanced Ready-to-eat foods for healthy and vulnerable Consumers”. The 5 L. monocytogenes strains came from the National 


\section{REFERENCES}

384 Alpas, H., Kalchayanand, N., Bozoglu, B., \& Ray, B. (2000). Interactions of high hydrostatic 385 pressure, pressurization temperature and $\mathrm{pH}$ on death and injury of pressure-resistant and 386 pressure-sensitive strains of foodborne pathogens. International Journal of Food Microbiology, 60, 33-42.

Angelidis, A. S., Boutsiouki, P., \& Papageorgiou, D. K. (2010). Loss of viability of Listeria monocytogenes in contaminated processed cheese during storage at 4,12 and $22^{\circ}$ C. Food Microbioliogy, 27, 809-818.

392

Angelidis, A. S., Smith, L. T., \& Smith, G. M. (1999). Compatible solute accumulation by Listeria monocytogenes grown on milk whey. FASEB Journal, 13, 1533-1533.

Behravesh, C., Jones, T. F., Vugia, D. J., Long, C., Marcus, R., Smith, K., et al. (2011). Deaths 397 associated with bacterial pathogens transmitted commonly through food: foodborne diseases active surveillance network (FoodNet), 1996-2005. Journal of Infectious Diseases, 204, 263267.

400

401

Brillet A., Pilet M. F., Prévost H., Cardinal M., \& Leroi F. (2005). Effect of inoculation of 402 Carnobacterium divergens V41, a biopreservative strain against Listeria monocytogenes risk, on the microbiological, and sensory quality of cold-smoked salmon. International Journal of Food Microbiology, 104, 309-324.

405

Bull, M. K., Hayman, M. M., Stewart, C. M., Szabo, E. A., \& Knabel, S. J. (2005). Effect of 407 prior growth temperature, type of enrichment medium, and temperature and time of storage on 
recovery of Listeria monocytogenes following high pressure processing of milk. International Journal of Food Microbiology, 101, 53-61.

Cheftel, J. C. (1995). Review: High-pressure, microbial inactivation and food preservation/Revision: Alta-presion, inactivacion microbiologica y conservacion de alimentos. Food Science and Technology International, 1, 75-90.

Chung, Y. K., Vurma, M., Turek, E. J., Chrism, G. W., \& Tousef, A. E. (2005). Inactivation of barotolerant Listeria monocytogenes in sausage by combination of high-pressure processing and food grade additives. Journal of Food Protection, 68, 744-750.

Chung, H. J. \& Yousef, A. E. (2010). Synergistic effect of high pressure processing and Lactobacillus casei antimicrobial activity against pressure resistant Listeria monocytogenes. New Biotechnology, 27, 403-408.

EFSA (European Food Safety Authority) (2015). The European Union summary report on trends and sources of zoonoses, zoonotic agents and food-borne outbreaks in 2013. EFSA Journal, 2015, 13:3991.

Faith, N.G., Parniere, N., Larson, T., Lorang, T.D., \& Luchansky, J.B. (1997). Viability of Escherichia coli O157:H7 in pepperoni during the manufacture of sticks and the subsequent storage of slices at 21, 4 and 20C under air, vacuum and CO2. International Journal of Food Microbiology, 37, 47-54. 
Gálvez, A., Abriouel, H., López, R. L., \& Omar, N. B. (2007). Bacteriocin-based strategies for food biopreservation. International Journal of Food Microbiology, 120, 51-70.

434

Hado, B. H., Yousef, A. E., (2007). Characteristics of Listeria monocytogenes important to food processors. In: Ryser, E.T., Marth, E.H. (Eds.), Listeria, Listeriosis and Food Safety (3 ${ }^{\text {rd }}$ ed.) (pp. 157-213) Boca Raton, FL, USA: CRC Press.

438

439

Holzapfel, W. H., Geisen, R., \& Schillinger, U. (1995). Biological preservation of foods with reference to protective cultures, bacteriocins and food-grade enzymes. International Journal of Food Microbiology, 24, 343-362.

442

443

Ihnot, A. M., Roering, A. M., Wierzba, R. K., Faith, N. G., \& Luchansky, J. B. (1998). Behavior of Salmonella Typhimurium DT104 during the manufacture and storage of pepperoni. International Journal of Food Microbiology, 40, 117-121.

Jofré, A., Garriga, M., \& Aymerich, T. (2008). Inhibition of Salmonella sp., Listeria monocytogenes and Staphylococcus aureus in cooked ham by combining antimicrobials, high hydrostatic pressure and refrigeration. Meat Science, 78, 53-59.

450

451 Johnsen, B. O., Lingaas, E., Dag Torfoss, Strøm, E. H., \& Nordøy, I., (2010). A large outbreak 452 of Listeria monocytogenes infection with short incubation period in a tertiary care hospital. 453 Journal of Infection, 61, 465-470. 
455 Kalchayanand, N., Sikes A, Dunne C. P, \& Ray B. (1998). Interaction of hydrostatic pressure, 456 time and temperature of pressurization and pediocin AcH on inactivation of foodborne bacteria. 457 Journal of Food Protection, 61, 425-431.

458

459 Jung, L.S., Lee, H.Y., Lee, S.H., Kim, S., \& Ahn, J. (2013). Assessment of pressure-induced 460 inactivation of Listeria monocytogenes exposed to low pHs. Food Science and 461 Biotechnology, 22, 99-105.

462

463 Linton, M., McClements, J. M. J., \& Patterson, M. F. (1999). Survival of Escherichia 464 coli O157:H7 during Storage in Pressure-Treated Orange Juice. Journal of Food Protection, 9, $465975-1096$.

466

467

Liu, G., Wang, Y., Gui, M., Zheng, H., Dai, R., \& Li, P. (2012). Combined effect of high hydrostatic 468 pressure and enterocin LM-2 on the refrigerated shelf life of ready-to-eat sliced vacuum packed cooked 469 ham. Food Control, 24, 64-71.

Lorentzen, G., Ytterstad, E., Olsen, R.L, Skjerdal, T., 2010. Thermal inactivation and growth potential of Listeria innocua in rehydrated salt-cured cod prepared for ready-to-eat products. Food control, 21, 1121-1126.

477 bacteria against Listeria monocytogenes in sliced cooked cured pork shoulder stored under 478 vacuum or modified atmosphere at $4 \pm 2^{\circ}$ C. Food Microbiology, 20, 259-265. 
Mertens, B., \& Deplace, G. (1993). Engineering aspects of high pressure technology in the food industry. Food Technology, 47, 164-169.

482

Mol, J. H. H., Hietbrink, J. E. A., Mollen, H. W. M., \& van Tinteren, J. (1971). Observations

on the microflora of vacuum packed sliced cooked meat products. Journal of Applied Bacteriology, 34, 377-397.

486

Pal, A., \& Ramana, K. V. (2009). Isolation and preliminary characterization of a nonbacteriocin antimicrobial compound from Weissella paramesenteroides DFR-8 isolated from cucumber (Cucumis sativus). Process Biochemistry, 44, 499-503.

490

491

Park, S. W., Sohn, K. H., Shin, J. H., \& Lee, H. J. (2001). High hydrostatic pressure inactivation 492 of Lactobacillus viridescens and its effect on ultrastructure of cells. International Journal of Food Microbiology, 36, 775-781,

Patterson, M. F., Mackle, A., \& Linton, M. (2011). Effect of high pressure, in combination 496 with antilisterial agents, on the growth of Listeria monocytogenes during extended storage of cooked chicken. Food Microbiology, 28, 1505-1508.

Patterson, M. F., McKay, A. M., Connolly, M., \& Linton, M. (2010). Effect of high pressure 500 on the microbiological quality of cooked chicken during storage at normal and abuse refrigeration temperatures. Food Microbiology, 27, 266-273. Microbiology, 98, 1400-1409. 
504

505

506

507

508

509

510

511

512

513

514

515

516

517

518

519

520

521

522

523

524

525

526

527

528

Pilet, M. F., \& Leroi, F. (2011). Applications of protective cultures, bacteriocins and bacteriophages in fresh seafood and seafood products. In: Lacroix, C. (Ed.), Protective cultures, antimicrobial metabolites and bacteriophages for food and beverage biopreservation (pp. 324-347) Zurich, Switzerland: Woodhead Publishing.

Scallan, E., Hoekstra, R. M., Angulo, F.J., Tauxe, R.V., Widdowson, M.A., Roy, S.L., Jones, J.L., \& Griffin, P.M. (2011). Foodborne illness acquired in the United States-major pathogens. Emerging and Infectious Diseases, 17, 7-15.

Shi, W., Qingping, W., Jumei Z., Moutong, C., Zean, Y. (2015). Prevalence, antibiotic resistance and genetic diversity of Listeria monocytogenes isolated from retail ready-to-eat foods in China. Food Control, 47, 340-347.

Smith, K., Mendonca, A., \& Jung, S. (2009). Impact of high-pressure processing on microbial shelf-life and protein stability of refrigerated soymilk. Food Microbiology, 26, 794-800.

Srionnual S., Yanagida F., Lin L. H., Hsiao K. N., \& Chen Y. S. (2007). Weissellicin 110, a newly discovered bacteriocin from Weissella cibaria 110, isolated from plaa-som, a fermented fish product from Thailand. Applied and Environmental Microbiology, 73, 2247-2250.

Stephan, R., Althaus D., Kiefer, S., Lehner, A., Hatz, C., Schmutz, C., Jost M., Gerber, N., Baumgartner, A., Hachler, H., Mausezahl-Feuz, M. (2015). Foodborne transmission of Listeria monocytogenes via ready-to-eat salad: A nationwide outbreak in Switzerland, 2013-2014. Food Control, 57, 14-17. 
529 Stratakos, A., \& Ch. Koidis, A. (2015). Suitability, efficiency and microbiological safety of novel physical technologies for the processing of ready-to-eat meals, meats and pumpable products. International Journal of Food Science and Technology DOI: 10.1111/ijfs.12781.

532

533 Stratakos, A. Ch., Delgado-Pando, G., Linton, M., Patterson, M. F., \& Koidis, A. (2015a).

Synergism between high-pressure processing and active packaging against Listeria monocytogenes in ready-to-eat chicken breast. Innovative Food Science and Emerging Technologies, 27, 41-47.

Stratakos, A. Ch., Linton, M., Patterson, M. F., \& Koidis, A. (2015b). Effect of high pressure processing on the shelf-life, safety and organoleptic characteristics of lasagne-ready meals during storage at refrigeration and abuse temperature. Innovative Food Science and Emerging Technologies. In Press.

542

Swaminathan, B., \& Gerner-Smidt, P. (2007). The epidemiology of human listeriosis. Microbes and Infection, 9, 1236-1243.

545

Tahiri, I., Desbiens, M., Kheadr, E., Lacroix, C., \& Fliss I. (2009). Comparison of different application strategies of divergicin M35 for inactivation of Listeria monocytogenes in cold smoked wild salmon. Food Microbiology, 26, 783-93.

Tholozan, J. L., Ritz, M., Jugiau, F., Federighi, M., \& Tissier, J. P. (2000). Physiological effects 551 of high hydrostatic pressure treatments on Listeria monocytogenes and Salmonella typhimurium. Journal of Applied Microbiology, 88, 2002-2021. 
554 Tyrovouzis, N. A., Angelidis, A. S., \& Stoforos, N. G. (2014). Bi-phasic growth of Listeria 555 monocytogenes in chemically defined medium at low temperatures. International Journal of 556 Food Microbiology, 186, 110-119.

557

558 Vermeiren, L., Devlieghere, F., De Graef, V., \& Debevere, J. (2004). Evaluation of meat born 559 lactic acid bacteria as protective cultures for the biopreservation of cooked meat products. 560 International Journal of Food Microbiology, 96, 149-164.

561

562 Werber, D., Hille, K., Frank, C., Dehnert, M., Altmann, D., Müller-Nordhorn, J., et al. (2013).

563 Years of potential life lost for six major enteric pathogens, Germany, 2004-2008. Epidemiology 564 and Infection, 141, 961-968.

565

566

567 
FIGURE LEGENDS

569

\section{$570 \quad$ Figure 1}

571 Changes in the L. monocytogenes counts (A and C) on low-pH RTE salads during storage at 4

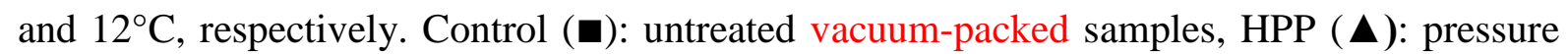
treated vacuum-packed samples (400 MPa for $1 \mathrm{~min}$ ), PC (X): vacuum-packed samples inoculated with $W$. viridescens, HPP/PC ( $)$ : combination of high-pressure and protective culture. Changes in the $W$. viridescens counts (B and D) on low-pH RTE salads during storage at 4 and $12^{\circ} \mathrm{C}$, respectively. PC $(\mathbf{X})$ : vacuum-packed samples inoculated with $W$. viridescens, HPP/PC ( ): combination of high-pressure and protective culture. Each point in the figure represents the mean of three separate trials. The error bars represent \pm S.D. Dashed line represents the limit of enumeration.

580

581

582

Figure 2

583

Changes in the L. monocytogenes counts (A and C) on higher pH RTE salads during storage at 4 and $12^{\circ} \mathrm{C}$, respectively. Control $(\boldsymbol{\square})$ : untreated vacuum-packed samples, HPP $(\boldsymbol{\Delta})$ : pressure treated vacuum-packed samples (400 MPa for 1 min), PC (X): vacuum-packed samples inoculated with $W$. viridescens, HPP/PC (४): combination of high-pressure and protective culture. Changes in the $W$. viridescens counts (B and D) on higher $\mathrm{pH}$ RTE salads during storage at 4 and $12^{\circ} \mathrm{C}$, respectively. PC (X): vacuum-packed samples inoculated with $W$. viridescens, HPP/PC ( $\diamond)$ : combination of high-pressure and protective culture. Each point in the figure represents the mean of three separate trials. The error bars represent \pm S.D. 